\title{
SOLUTIONS FOR DEVELOPING E-TOURISM SERVICE BUSINESSES
}

\author{
Tran Xuan Loc \\ Ho Chi Minh City University of Technology (HUTECH), Ho Chi Minh City, Vietnam \\ Bui Anh Tuan \\ Foreign Trade University (FTU), Hanoi, Vienam
}

\begin{abstract}
The strong development of science and technology as well as the impact of the industrial revolution 4.0, businesses in general and service businesses in particular have been changing rapidly. In the context of a fundamental and profound change, the demand and behavior of the majority of consumers, the provision of products and services is forced to be tailored to meet these needs and behaviors. In the tourism field, the supply process, modes, diversification of products, the quality of tourism services are fundamentally changed according to the e-business model with the more and more enhancement to meet customer needs. This paper researches and proposes solutions to develop e-tourism service businesses effectively.
\end{abstract}

Key words: Solution, Development, E-Tourism Service Business.

Cite this Article: Tran Xuan Loc and Bui Anh Tuan, Solutions for Developing E-Tourism Service Businesses, International Journal of Management, 11(12), 2020, pp. 2352-2356.

http://iaeme.com/Home/issue/IJM?Volume=11\&Issue $=12$

\section{INTRODUCTION}

According to eMarketer statistics, the worldwide trend with global trade, buy and sell in 24 hours a day, as well as cost savings, global e-commerce revenue increases 400 billion USD from 2012 to 2014. Markets such as Central and Eastern Europe, Latin America, Middle East and Africa have mostly grown very low. The traditional e-commerce markets such as North America and Western Europe have stable growth. Since 2014, Asia Pacific has surpassed North American market to become the largest e-commerce market in the world. In 2016, total ecommerce revenue from the Asia-Pacific market was higher than North America and Europe combined (Fortes and Rita, 2016).

Vietnam is a member of the Asia Pacific e-commerce network, the ASEAN Economic Community has great potentials to develop e-commerce, but the development is still at a level not commensurate with the potential. In 2014, e-commerce revenue in ASEAN countries was only 7 billion USD. This is a very small number compared to e-commerce revenue in the entire 
Asia Pacific region, but the strong development is based on demographic factors, internet socialization speed and growth rate of e-commerce services is inevitable.

Currently the number of e-commerce users in Southeast Asia is 87 million, approximately 86 million users in Japan. However, the average spending per person is only about 7 USD compared to 119 USD in Japan. If Southeast Asian countries have the right strategy, ecommerce in the region will take off in 2017.

Vietnam is a densely populated country with the top speed of internet socialization in the region. Vietnam has a lot of potential to develop an e-tourism service business. Currently, Vietnam has about 15 million people using e-commerce for different purposes. According to ASEAN statistics, $50 \%$ of air tickets sold in Vietnam are distributed via the internet. In addition, this statistic also shows that booking services and airline tickets are the two most used services in Southeast Asia. However, in order to become a strategic business, many factors are required from the suppliers, the government, and the users in the e-tourism service business. Currently, there are many issues that need to be considered in developing e-commerce such as e-payment service, user interface, merchant reputation and several other factors.

It is obvious that this is a potential commercial market but there are not many researches on this field. This paper analyzes and proposes solutions for developing an e-tourism service business which create a premise for researchers, enterprises and governments to promote business expansion in tourism in the period of international integration.

The remainder of this paper is organized as follows. The e-tourism service business is presented in Section 2. The development solutions for an e-tourism service business is proposed in Section 3. Finally, there is a summary of this research.

\section{E-TOURISM SERVICE BUSINESS}

The internet has currently grown and spread around the world. It is easy to access the network, communicate with other people and enterprises, even governments on the internet at low cost, fast speed and friendly. This is a reason why the number of people utilizes the network more and more. Then the potential customers for businesses in general and especially tourism businesses in particular emerged. Before deciding to book a tour; and choose a destination, and service, customers always tend to search for information, compare prices and services on the internet and then make a decision. Therefore, tourism businesses that can reach and persuade customers will be the winners in the market (Erkan and Evan, 2016).

Electronic tourism (E-toursim) is defined as the application of information and communication technologies (ICT) to the tourism. Similarity, an e-tourism is the digitization of all processes and value chains in the tourism, hotel, service industry... with the aim of maximizing the efficiency of tourism service businesses (Bhatiasevi and Yoopetch, 2015).

The concept of e-tourism is broadly understood as e-commerce, e-marketing, e-finance, eaccounting, e-shopping... as well as strategy, plan and all aspects of the tourism are digitized. Therefore, e-tourism undertakes three main divisions: business administration, information system management and finally, tourism business.

Traditional and e-tourism service businesses have the following distinctive features.

The first is the speed issue. In the era of information technology and knowledge, speed is a very important factor. The e-tourism service business is the one that fully responds to the speed requirements for both the tourism service provider and the traveler. For service providers, product information is generated simultaneously with the product manufacturing process. This creates a competitive advantage over competitors in attracting customers. In addition, manufacturers also get feedback from customers more quickly. For customers, access to information about products and services is done faster and easier. Moreover, the transaction 
process is also processed faster due to saving time in dealing, delivering and special payment for digital goods.

The second is the continuous operation time. The e-tourism service business eliminate the physical obstacles. It is obvious that the traditional service business is good, but it may not work $24 / 24$ hours a day which can be implemented in the online. The e-tourism service business is capable of working continuously at any time, 24 hours a day and 7 days a week. This means that there is absolutely no concept of death of time.

The third is the global scope. The internet has the ability to penetrate all over the world, helping businesses to promote fully products to consumers around the world with low cost and fast time. The e-tourism service business overcomes all obstacles in the death of distance. The market of the e-tourism service businesses is unlimited and allows businesses to fully exploit the global market.

The fourth is to eliminate obstacles caused by intermediaries. In the traditional form, the products reach the end consumer, they usually have to go through many intermediaries such as wholesalers, retailers, agents, brokers... significantly reducing the competitive advantage of businesses when participating in the market, especially on price. Service fees and commissions have significantly increased the selling price of the products.

Additionally, the obstacle of the traditional form is that businesses do not have a direct relationship with consumers. Therefore, the feedback is often inaccurate and incomplete and enterprises' response to market changes is often not timely. Meanwhile, the e-tourism service businesses ignore intermediaries as well as directly contact with customers, collect timely and accurate information to serve production and business processes for meeting customer's needs (Vecita, 2013).

It is obvious that tourism products are one of the most popular e-tourism service business products that are compared with other e-products and services such as computer software, computer hardware, airline tickets, books,... When the consumers search to buy general products, they need to know price, quality and payment form. For tourism services, customers are informed more about tourism knowledge; new and interesting destinations; and other updated information (Yoon and Barker, 2013).

The technology development has currently created a very favorable environment for the development of the e-tourism services. This makes tourism services more and more rich and lively. Simultaneously, the business is not limited by display space; and therefore, it is possible to trade many various products and services. With the help of the technology, tourism products also come alive with photos and videos of destinations. Additionally, tourism businesses also easily adjust their services according to the needs and tastes of customers. Therefore, customers have more options to suit their needs (San and Herrero, 2012).

Tourism businesses have recently faced some difficulties such as more and more e-tourism businesses. Therefore, besides diversified services, tourism businesses need to offer reasonable prices and good service quality to be able to compete with other tourists on the market. It is required that the e-tourism businesses need to build a complete system including how to display services, forms of payment and after-sales service to customers.

Based on these analyzes, solutions are proposed to develop an e-tourism service business, respectively.

\section{SOLUTIONS FOR DEVELOPING E-TOURISM SERVICE BUSINESSES}

Solutions for developing e-tourism service businesses include direct and indirect ones as follows. 


\subsection{Solutions for improving usability}

In order to increase the intention of using e-tourism services, tourism service businesses need to improve the usefulness of the service through the creation of a variety of service amenities.

\subsection{Solutions for improving ease of use}

The usefulness factor is positively influenced by ease of use service. Therefore, in order to improve the usefulness, businesses need to design application content and website that is easy to use for customers when booking tours or hotels. Ease of use not only has a positive effect on the usability but also positively affects attitude towards the service. It is obvious that the ease of use of the system has an indirect effect on the intention to use an e-tourism service business.

\subsection{Solutions for improving customer attitudes to services}

The attitude factor of the service has a direct impact on the intention to use e-tourism services. Simultaneously, the ease of use, perceived risk, usefulness and destination image have a positive effect on attitude. Therefore, in order to improve customer attitudes to the service, businesses not only need to improve ease of use and usefulness, but also pay attention to the enterprises' image and reduce the perceived risk of customers.

\subsection{Solutions for improving the system's information security}

The factors of information security have a positive effect on ease of use and perceived risk. Therefore, it can seen that an issue exists in building an e-tourism service business system. The more secure the system is set up, the more complex customers experience using it. This is a trade-off value between the benefits of information security and the ease of using the service.

Therefore, the e-tourism service businesses need to design systems that are safe but must be easy to use so that customers do not have trouble or lose time when manipulating.

\subsection{Solutions for improving confidence in the system}

The trust in the system makes to reduce the system's perceived risk. If the e-tourism service businesses build systems that bring trust to customers, the customers will tend to reduce risk anxiety. Then, the attitude and intention to use the service will increase. Therefore, it is necessary to improve customer confidence in the system of the e-tourism service businesses.

\subsection{Solutions for improving customer readiness to pay}

The payment willingness affects the intention of customers to choose for utilizing tourism services. Therefore, the improvement of the customer's payment readiness with the service will help increase customer intentions. Then, the businesses can access higher customer options.

\section{CONCLUSION}

The achieved analysis shows that the development of e-tourism service business activities not only brings the benefits for each individual customer using the service, but also brings the profits for the e-tourism service enterprises. The broad-based development contributes and improves the situation, level and growth rate for the e-tourism service industry and the relevant industries. Simultaneously, it is realized that the intent-to-use analysis, willingness to pay, usefulness have a direct and positive affect on the e-tourism service businesses. The solutions are proposed for the purpose of developing e-toursim service businesses. 


\section{REFERENCES}

[1] Fortes, N., and Rita, P. (2016). Privacy concerns and online purchasing behaviour: Towards an integrated model. European Research on Management and Business Economics, 22(3), 167176.

[2] Erkan, I., and Evans, C. (2016). The influence of eWOM in social media on consumers' purchase intentions: An extended approach to information adoption. Computers in Human Behavior, 61, 47-55.

[3] Bhatiasevi, V., and Yoopetch, C. (2015). The determinants of intention to use electronic booking among young users in Thailand. Journal of Hospitality and Tourism Management, 23, 1-11.

[4] Vietnam, E-commerce and Information Technology Agency (VECITA). (2013). Vietnam Ecommerce Report.

[5] Yoon, H. S., and Barker Steege, L. M. (2013). Development of a quantitative model of the impact of customers' personality and perceptions on Internet banking use. Computers in Human Behavior, 29(3), 1133-1141.

[6] San Martín, H., and Herrero, Á. (2012). Influence of the user's psychological factors on the online purchase intention in rural tourism: Integrating innovativeness to the UTAUT framework. Tourism Management, 33(2), 341-350. 